\title{
Alternate Modulation of Biological Activity of Stress Molecule, $\beta$-D-glucopyranosyl-cholesterol, by Chemical Modification of Sugar Moiety \\ Hypotheses concerning biochemical meaning of the new glycosides
}

\begin{abstract}
DUMITRU PETRU IGA ${ }^{1 *}$, DUMITRU POPESCU², SILVIA GITMAN ${ }^{1}$
UUniversity of Bucharest, former C. I. Parhon, 36-46 M. Kogalniceanu Blvd, 050107, Bucharest, Romania ${ }^{2}$ Gh. Mihoc-Caius lacob Institute of Mathematical Statistics and Applied Mathematics of Romania Academy, 13 Calea 13 Septembrie, 050711, Bucharest, Romania

We have synthesized, beside the presently consecrated stress molecule, $\beta$-D-glucopyranosyl-cholesterol, $\beta$-D-arabinopyranosyl-, $\alpha$-L-arabinofuranosyl-and $\beta$-and $\alpha$-D-(3-0-methyl)glucopyranosyl-cholesterol. Two types of glycosylation agents were used: peracylated sugar bromide, with $\mathrm{CdCO}_{3}$ as promotor, and peracetylated sugar in the presence of $\mathrm{BF}_{3} \cdot \mathrm{OBu}_{2}$ as promoting agent, respectively. A chemical test was used for synthesis monitoring: Zemplén saponification of reaction mixture had to produce an amphiphilic glycoside migrating in the region of cerebrosides, by TLC in a suitable solvent system. All intermediates and final products have been characterized by ${ }^{1} \mathrm{H}$ and ${ }^{13} \mathrm{C}$ NMR spectroscopy as well as by chemical and chromatographical methods. In the virtue of the recently discovered biochemical relationships of cholesterol and cerebrosides (or glycosterols and ceramide) new biochemical hypotheses have been advanced concerning the meaning of these new glycosides.
\end{abstract}

Keywords: L-arabinopyranose, L-arabinofuranose, 3-0-methyl D-glucose, cholesterol, glycosterol, NMR spectra

Glycosterols (GSts) are complex amphiphilic glycosides with a large distribution in living matter. They have a monoor oligosaccharidic part, neutral or ionic, as a polar head, and a hydrophobic tail formed of sterol [1].

Important biochemical and physiological functions have been attributed to GSts in the last years: they are involved in stress phenomena [2,3], they are glycosylation donors to ceramides in plant cells $[4,5]$ and they serve as primer molecules in cellulose biosynthesis [6] or other natural polymers as heparan sulfate [7]. An astounding discovery of this century, concerning lipids metabolism, is biochemical interchange of sugar between cerebrosides and sterols and of GSts with ceramide [8]. GSts of some microorganisms are antigens and are increasingly used for the diagnosis of specific diseases $[9,10]$.

Discovery of GSts in natural vegetable materials has to be associated with the discovery of the first partially methylated sugar, in the same glycoconjugate [11]. The methylated sugar is 3-0-methyl-D-fucose (digitalose) and the aglycone, digitaligenin. $\beta$-D-Glucopyranosyl-cholesterol was discovered in 1913 in some vegetable tissues [12], and in the same year was synthesized [13], as an application of by then invented Koenigs-Knorr glycosylation reaction [14]. However, its biochemical and physiological role was discovered only eight decades later $[3,5,6,8]$.

In this paper, the glycosides of cholesterol with $\alpha$-Larabinopyranose, $\alpha$-L-arabinofuranose and $\beta$ - and $\alpha$-D-(30 -methyl)glucopyranose have been synthesized and characterized by chemical, chromatographical and spectral ( ${ }^{1} \mathrm{H}$ and ${ }^{13} \mathrm{C}$ NMR) means.

\section{Experimental part}

Materials and methods

D-Glucose, L-arabinose and methyl iodide (Mel) were from Sigma. All reagents used were either from Fluka or from Merck and they were of analytical grade. Solvents were freshly distilled before their use.
The ${ }^{1} \mathrm{H}$ and ${ }^{13} \mathrm{C}$ NMR spectra of synthesis intermediates and products were measured in $\mathrm{CDCl}_{3}$ containing TMS. One-dimensional NMR experiments were performed on a Bruker Avance DRX 400 spectrometer using 400 and 100 $\mathrm{MHz}$ for the ${ }^{1 \mathrm{H}}$ and ${ }^{13} \mathrm{C}$ frequencies, respectively. The ${ }^{1} \mathrm{H}-{ }^{-1} \mathrm{H}$ correlation spectroscopy (COSY) and ${ }^{1} \mathrm{H}-{ }^{13} \mathrm{C}$ heteronuclear multiple quantum coherence (HMQC) experiments were carried out with an inverse probe.

Peracylation of monosaccharides, activation as peracylated sugar bromide and glycosylation reactions were made as indicated in previous papers [15-17]. A small portion of glycosylation acceptor, cholesterol was acetylated and its NMR spectra registered. NMR Spectra of peracetylated glycosides were also compared with the NMR spectra of corresponding peracetylated monosaccharides. All chemical transformations were monitored by TLC and the following solvent systems (SS) were used: SS 1, toluene-ethanol 3/1 (v/v); SS 2, chloroform-methanol 19/1 (v/v); SS 3, hexane-ethyl acetate 1/1 (v/v); SS 4, chloroform-methanol-acetone-AcOH-aq 10/2/4/2/1 (v/v); SS 5 chloroform-methanol-aq 60/25/4 (v/v); SS 6 chloroform-methanol-aq 50/10/1 (v/v). Reaction products were separated by column chromatography on silicagel, in unprotected state. A fine tune of polarity of eluting solvents allowed the separation of all glycosides, diastereomers inclusively $[15,17]$. The chemical constituents of GSts were determined after acidic hydrolysis and partition between water and chloroform: sugars by anthrone, and cholesterol by LiebermanBurchardt method. Tetra-0-acetyl- $\alpha \beta$-L-arabinopyranose was synthesized by peracetylation of the monosaccharide with sodium acetate/acetic anhydride and the peracetylation product was used for glycosylation. TetraO-benzoyl- $\alpha \beta$-L-arabinofuranoside was synthesized by perbenzoylation of the sugar with benzoyl chloride at the boiling point of pyridine, followed by conversion of the ester

\footnotetext{
*email pdiga49@yahoo.com
} 
to tri-0-benzoyl-á-L-arabinofuranosyl bromide, which served as glycosyl donor [15,17].

3-0-Methyl-D-glucose was prepared as indicated [18] and then alternatively peracetylated or perbenzoylated. A standard curve with 3-0-methyl-D-glucose was constructed for anthrone determination of this sugar. Tetra0 -acetyl-3-0-methyl- $\alpha \beta$-D-glucopyranose served as glycosylation agent in the presence of $\mathrm{BF}_{3} \cdot \mathrm{OBu}_{2}$ [19]. Perbenzoylated sugar was converted to 1-bromo-2,4,6-tri0-benzoyl 3-0-methyl $\alpha \beta$-D-glucopyranose, by reaction with $\mathrm{HBr}$ in glacial acetic acid, and the organic bromide was used for glycosylation in the presence of $\mathrm{CdCO}_{3}$ as promotor. Glycosylation products of either method were submitted to Zemplen saponification and separated by silica gel column chromatography in a gradient of $\mathrm{MeOH}$ in $\mathrm{CHCl}_{3}$ [15]. A small portion of either GSt was peracetylated and analyzed by NMR spectroscopy.

\section{Results and discussions}

Acylation and glycosylation reactions (Figs. 1 and 2) could be followed by TLC in SS1-SS6, some solvent mixtures, especially those containing chloroform, could also distinguish between furanosic and pyranosic isomers. Our experience with furanosides indicated that three methods are used for comparative characterization of furanosides and pyranosides: NMR spectra, Malaprade oxidation and enzymatic hydrolysis. However, only two methods are really infallible in unequivocal characterization of the two isomers, especially in a resolution between 5substituted furanosides and 4-substituted pyranosides: NMR analysis and enzymatic cleavage. The latter is still undeveloped especially concerning furanosidases, which are preferentially produced by pathogenic microorganisms [20].
Acylation accompanied by heating, favors the formation of furanosic ring. Of this reason, solvents with relatively high b. p., are used as environment for acylation, e. g., DMF and DMSO.

Tetra-0-acetyl- $\alpha$-L-arabinopyranose (Fig. 1) had the expected NMR spectra [21-23]:

$\left({ }^{13} \mathrm{C} /{ }^{1} \mathrm{H} N M R ; \mathrm{CDCl}_{3} ; \delta \mathrm{ppm} ; / \mathrm{Hz}\right): 92.01 / 5.621(\mathrm{~d}, 6.8$ $\mathrm{Hz})(\mathrm{C} 1 / \mathrm{H} 1) ; 66.58 / 5.315(\mathrm{C} 2 / \mathrm{H} 2) ; 75.18 / 5.006(\mathrm{C} 3 / \mathrm{H} 3)$; 74.59/5.315 (C4/H4); 62.93/ 4.047 (C5/H5); 62.93/3.803 $\left(\mathrm{C} 5 / \mathrm{H}^{\prime}\right)$.

Tetra-0-benzoyl- $\alpha$-L-arabinofuranose (Fig. 1) was evidenced by the followin NMR signals [24-26]: $\left({ }^{13} \mathrm{C} /{ }^{1} \mathrm{H}\right.$ NMR; $\mathrm{CDCl}_{2} ; \delta$ ppm; J Hz): 99.21/6.153 (s) (C-1/H-1); $80.42 /$ 5.171 (C-2/H-2); 82.25/4.338 (C-3/H-3); 79.55/4.170 (C-4/ $\mathrm{H}-4) ; 64.45 / 4.301$ (C-5/H-5); 64.45/4.230 (C-5/H-5).

Tri-0-acetyl- $\alpha$-L-arabinopyranosyl cholesterol (Fig.

1) was proved by the following signals:

${ }^{13} \mathrm{C} /{ }^{1} \mathrm{H}$ NMR; $\mathrm{CDCl}$; $\delta$ ppm; J Hz) (Fig. 1): 99.87/4.490 (d, $7.2 \mathrm{~Hz})(\mathrm{C}-1 / \mathrm{H}-1) ; 70.45 / 5.016$ (C-2/H-2); 69.43/5.147 (C-3/H-3); 67.89/5.220 (C-4/H-4); 63.40/3.994 (C-5/H-5); 63.40/3.593 (C-5/H-5).

Tri-0-acetyl- $\alpha$-L-arabinofuranosyl cholesterol (Fig. 1) was proved by the following signals:

$\left({ }^{13} \mathrm{C} /{ }^{\mathrm{H}} \mathrm{H}\right.$ NMR; $\mathrm{CDCl}$; $\delta$ ppm; J Hz) (Fig. 1): 103.80/5.179 (s) (C-1/H-1); 79.90/4.253 (C-2/H-2); 81.81/5.051 (C-3/H3); $77.33 / 4.950$ (C-4/H-4); 63.34/4.393 (C-5/H-5); 63.34/ $4.239(\mathrm{C}-5 / \mathrm{H}-5)$.

$\beta-D-(3-0$-Methyl-tri-0-acetyl) glucopyranosylcholesterol (Fig. 2) presented the following signals: $\left({ }^{13} \mathrm{C} /\right.$ ${ }^{1} \mathrm{H}$ NMR; $\mathrm{CDCl}_{3} ; \delta$ ppm; J Hz): 100.0/4.39 (d, $\left.7.7 \mathrm{~Hz}, 1 \mathrm{H}\right)$ (C1/H1); 72.1/4.84 (dd, 8Hz, 1Hz, 1H) (C2/H2); 80.0/4.92 (t, $10 \mathrm{~Hz}, 1 \mathrm{H})(\mathrm{C} 3 / \mathrm{H} 3) ; 69.1 / 4.10(\mathrm{dd}, 5 \mathrm{~Hz}, 7 \mathrm{~Hz}, 1 \mathrm{H})(\mathrm{C} 4 /$ $\mathrm{H} 4$ ); 81.3/3.98 (dd, $2 \mathrm{~Hz}, 10 \mathrm{~Hz}, 1 \mathrm{H}$ ) (C5/H5); 62.6/3.44 (C6/ H6): $62.6 / 3.39$ (C6/H6): $58.3 / 3.29$ (s. $3 \mathrm{H})\left(\mathrm{CH}_{\text {. etheric }}\right.$

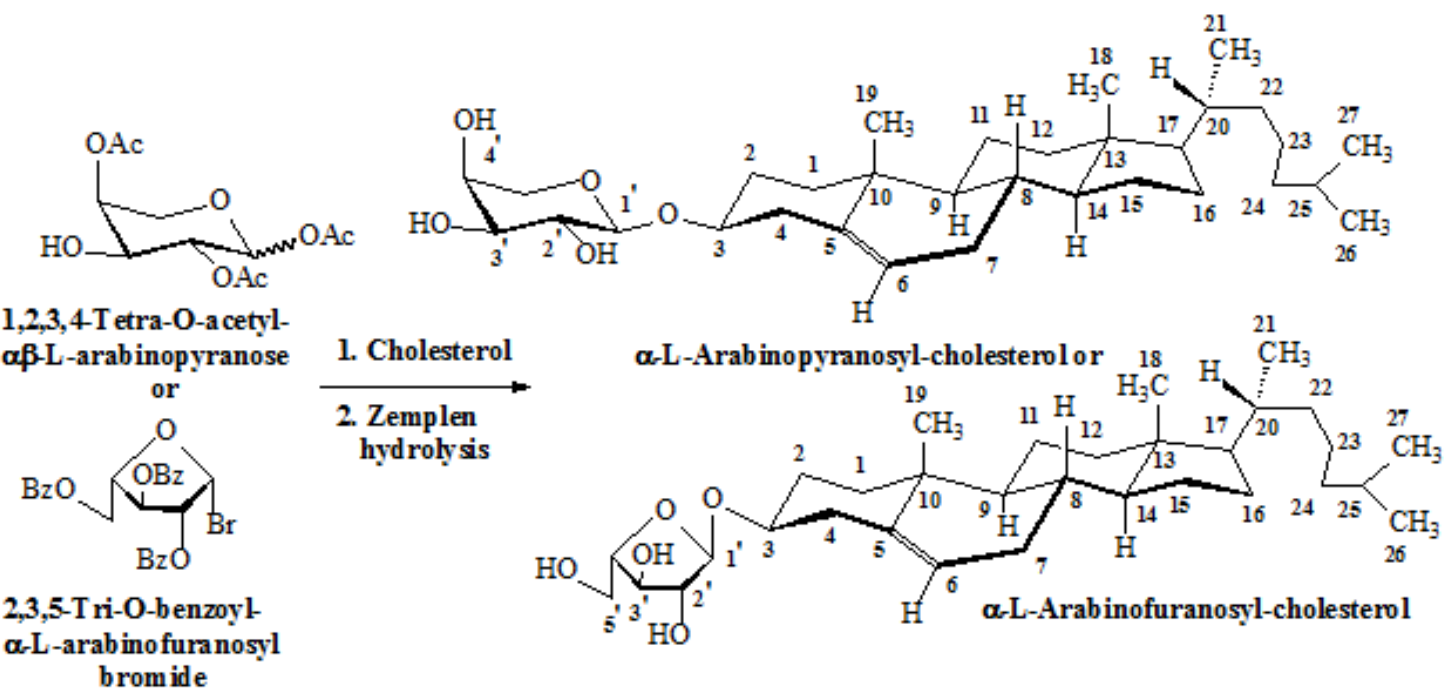

Fig.1. Preparation of glycosylation donors and synthesis of $\alpha$-L-arabinopyranosyl- and $\alpha$-L-arabinofuranosyl-cholesterol
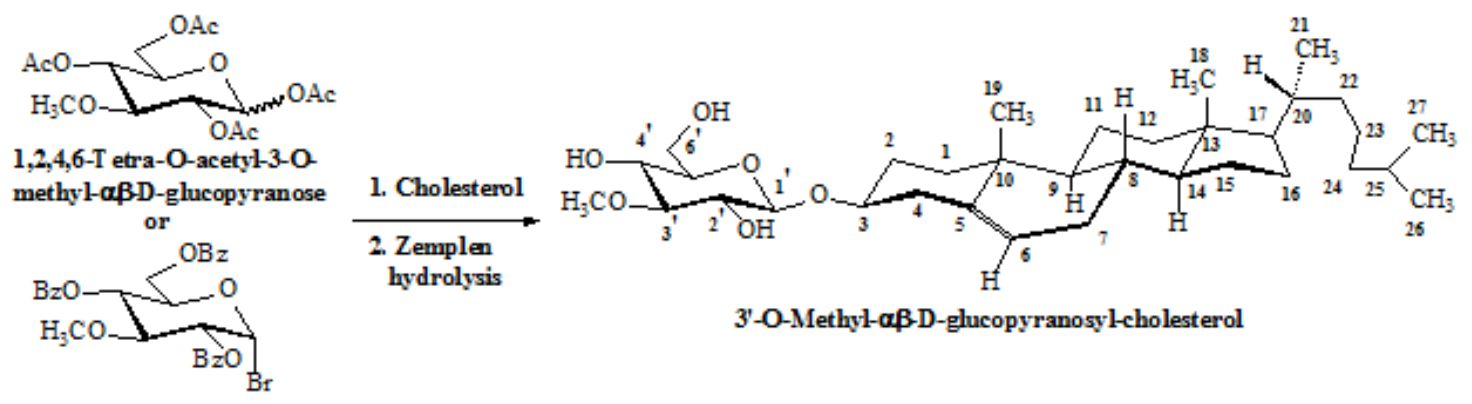

2,4,6-Tri-O-benzoyl-3-O methyl- $\alpha \beta-D-$ glucopyranosyl

Fig. 2. Synthesis of 3-0-methyl- $\alpha$ - and $\beta$-D-glucopyranosyl-cholesterol from two precursors 
group); ( $\mathrm{CH}_{3}$ of $\mathrm{Ac}$ groups); ( $>\mathrm{C}=0$ of $\mathrm{Ac}$ ); $72.0 / 3.46$ ( $\mathrm{C} 3$ cholest); $122.1 / 5.26$ (d, 5Hz) (C6 cholest); 11.99/0.58 (C18 cholest); 18.86/0.90 (C19 cholest).

$\alpha-D-($ 3-0-Methyl-tri-0-acetyl) glucopyranosylcholesterol (Fig. 2) presented the following signals: $\left({ }^{13} \mathrm{C} /\right.$ ${ }^{1} \mathrm{H}$ NMR; $\mathrm{CDCl}_{3} ; \delta$ ppm; J Hz): 99.5/5.4 (d, 4.6 Hz, 1H) (C1/ H1); $74.7 / 5.19$ (C2/H2); 78.9/5.53 (C3/H3); 68.2/4.84 (C4/ $\mathrm{H} 4) ; 79.4 / 4.40$ (C5/H5); 63.2/4.11 (C6/H6); 63.2/4.49 (C6/ $\mathrm{H} 6) ; 57.2 / 3.80(\mathrm{~s}, 3 \mathrm{H})\left(\mathrm{CH}_{3}\right.$ etheric group); $\left(\mathrm{CH}_{3}\right.$ of $\mathrm{AC}$ groups); ( $>\mathrm{C}=0$ of $\mathrm{AC}$ ); 73.9/3.42 ( $\mathrm{C} 3$ cholest); 140.5 ( $\mathrm{C} 5$ cholest); $122.2 / 5.31$ (d, 5Hz) (C6 cholest); 12.0 (C18 cholest); 18.8 (C19 cholest).

$\alpha$-L-Arabinopyranosyl cholesterol simultaneously presented the signals of pyranosic sugar [21-23] and of cholesterol, while its isomer presented the signals of furanosic monosaccharide [24-26] and the signals of cholesterol. Both glycosides produced L-arabinose and cholesterol in the molar ratio 1:1, by acidic hydrolysis. The diastereomers $\beta$ - and $\alpha$-D-(3-0-methyl) glucopyranosylcholesterol presented the NMR signals of partially methylated sugar [18] and of cholesterol. As indicated acidic hydrolysis and analytical data, they contained 3-0methyl-D-glucose and cholesterol in the molar ratio 1:1. The values of coupling constants indicated that both possessed pyranosic ring. As is known from chromatographic analysis, 3-0-methyl-D-glucose is less polar than D-glucose. Hence the two diastereomeric 3-0-methylglucopyranosides of cholesterol are less polar than their unmethylated counterparts. In all cases modification of molecule polarity, by chemical modification of hydroxy group(s) of glycosterol, will affect their compatibility with membrane.

Beside $\beta$-D-glucopyranosyl-cholesterol [16], we have synthesized $\beta$-D-(6-sulfo)- and $\beta$-D-(3,6-bissulfo) glucopyranosyl-cholesterol, by sulfation of the glucosterol with $\mathrm{ClSO}_{3} \mathrm{H}$ in pyridine [17]. Sulfate esters are much more polar than the parental glycoconjugate, due to the ionic sulfate. A continuation of these syntheses should be biological tests, especially on cells in culture. A number of GSts containing partially methylated carbohydrates have been discovered in natural materials: digitalin [11,27], GSts with 5-0-methyl-D-galactofuranose [28] or with 2-0-methylD-xylopyranose [29], 2-0-methyl-, 3-0-methyl- and 2,3di-O-methyl- $\beta$-D-xylopyranose [30]. A number of 16 GSts based on pregnane have been discovered in plants. Their constituent partially methylated sugars are: D-oleandrose, D-cymarose, and D-thevetose [31]. However, their biological role remains unknown.

An exceptional and spectacular biochemical property of glycosterols, discovered in this century [8], consists in their capacity to exchange sugar residue with ceramides, the result being free sterol and cerebrosides. Such properties are consecrated to the so-called Special Natural Reagents (ATP, NAD(P), FAD, etc.,) [32], and now they have been amazingly attributed to glycosterols. In fact, both glycosterols and glycosphingolipids present three alternatives concerning their polar, hydrophilic moiety: (1) unmodified pyranosic carbohydrates; (2) carbohydrates with furanosic ring; (3) partially methylated carbohydrates. And since sugar transfer was proved for glycosterols containing unmodified pyranosic carbohydrates, it seems plausible to extend this property to glycolipids based on furanosic and partially methylated carbohydrates.

Cholesterol is a chiral molecule possessing eight chiral centers, i. e., 256 isomers, and only one of these isomers is currently found in nature. Chemical synthesis of the enantiomer of natural cholesterol (ent-cholesterol) [33] is a proof that scholars still pay attention to this compound. We have defined chitwin molecules as being formed of two sets of identical chemical functions and two sets of identical chiral centers [34]. (The term chitwin is a contraction of the words chiral and twin). The simplest chitwin molecules are the enantiomers of tartaric acid, the enantiomers of threitol and of 2,3-butanediol. The enantiomers of mannitol and iditol are also chitwin compounds. A natural law discovered byE. Fischer, rather as a practical procedure than in an explicit manner, sounds in this way: symmetrical doubling of a molecule that is simply chiral, produces a chitwincompound. For his ideas, Fischer synthesized a number of chitwin compounds: trehalose, isotrehalose, gentiobiosyl- $\beta$ - $\beta$-gentiobiose, cellobiosyl- $\beta$ - $\beta$-cellobiose [35-37], homogenous diketoderivatives of natural amino acids [38]. Hence we may imagine cholesterol dimerization in two ways: (a) two molecules of the same type, either natural or entcholesterol would produce a chitwin system; (b) a hybrid dimerization, i. e., a natural molecule and an ent-one would lead to a symmetrical (meso) system. Hence symmetrical molecules are formed of two enantiomeric halves, while chitwin ones are formed of two identical halves. Symmetrical molecules are meso-tartaric acid, meso-2,3butanediol, galactitol, allitol, etc. Chitwin derivatives of cholesterol have been initially detected in a mixture of cholesterol and concd. sulfuric acid, as tetraenoic symmetrical dimers linked C-4-C-4' [39]. Then chitwin dimers of sterols have been found in natural materials $[40,41]$. On the other hand, it has been found out that by mixing cholesterol with phospholipids, some molecules of sterol associate as dimers, i. e., chitwin structures linked by physical linkages [42-44]. Moreover, by attaching of a series of residues to hydroxyl group [45] or a fluorescent group on the lateral chain [46-47] this behaviour was not affected. The following question might be raised: is there a natural chitwin force? It might be supposed that glycosterols, per se or partially methylated, could be more suitable to evidence such a phenomenon, due to their greater potential to form hydrogen bonds, in comparison with free sterols.

\section{Conclusions}

Glycosylation of cholesterol with peracetylated free or partially methylated carbohydrates, in the presence of $\mathrm{BF}_{3} . \mathrm{OBu}_{2}$, produces the expected glycosterols.

$\mathrm{CdCO}_{3}$ is a suitable promotor for glycosylation of natural or synthetic aglycones with peracylated sugar bromide.

Application of the discovery of stress molecule and phenomenon has to be preceded by preparation and investigation of a large variety of sterol glycosides.

Acknowledgment. Thanks are due to Prof. Dr. Richard R. Schmidt, Konstanz University, Germania, for the laboratory equipment.

\section{References}

1. IGA, D. P., IGA, S. Trends Org. Chem., 2012, 16, 13-68.

2. KUNIMOTO, S., KOBAYASHI, T., KOBAYASHI, S., MURAKAMIMUROFUSHI, K. Cell Stress \& Chaperones, 2000, 5, 3-7.

3. KUNIMOTO, S., MUROFUSHI, W., KAI, H., ISHIDA, Y., UCHIYAMA, A., KOBAYASHI, T., KOBAYASHI, S., MUROFUSHI, H., MURAKAMIMUROFUSHI, K. Cell Struct. Function, 2002, 27, 157-162.

4. LYNCH, D. V., CRISS, A. K., LEHOCZKY, J. L., BUI, V. T. Arch. Biochem. Biophys., 1997, 340, 311-316.

5. CANTATORE, J. L., MURPHY, S. M., LYNCH, D. V. Biochem. Soc. Trans., 2000, 28, 748-750.

6. PENG, L., KAWAGOE, Y., HOGAN, P., DELMER, D. Science, 2002, 295, 147-150.

7. LUGEMWA, F. N., ESKOZ, J. D. J. Biol. Chem., 1991, 266, 6674-6677. 8. MARQUES, A. R. A., MIRZAIAN, M., AKIYAMA, H., WISSE, P., FERRAZ, M. J., GASPAR, P., et al. J. Lipid Res., 2016, 57, 451-463. 
9. HAQUE, M., HIRAI, Y., YOKOTA, K., MORI, N., JAHAN, I., ITO, H., HOTTA, H., YANO, I., KANEMASA, Y., OGUMA, A. J. Bacteriol., 1996, 178, 2065-2070.

10. BEN-MENACHEM, G., KUBLER-KIELB, J., COXON, B., YERGEY, A., SCHNEERSON, R. Proc. Natl. Acad. Sci. U. S. A., 2003, 100, 7913-7918. 11. KILIANI, H. Arch. Pharm., 1892, 230, 250-261.

12. POWER, F. B., SALWAY, A. H. J. Chem. Soc., 1913, 103, 399-406.

13. SALWAY, A. H. J. Chem. Soc. 1913, 103, 1022-1029.

14. KOENIGS, W., KNORR, E. Ber. Deut. Chem. Ges. 1901, 34, 957-981. 15. IGA, D. P., IGA, S., SCHMIDT, R. R., BUZAS, M. C. Carbohydr. Res. 2005, 340, 2052-2054.

16. PREDESCU, N. F., IGA, S., IGA, D. P., BADEA, F. Roum. Biotechnol. Lett. 2006, 11, 2521-2527.

17. IGA, S., IGA, D. P., PREDESCU, N. F., IGA, A., NICOLESCU, A. Rev. Chim. 2008, 59, 1152-1155.

18. GITMAN, S. S., DUICA, F., NICOLESCU, A., IGA, D. P. Rev. Chim. 2015, 66, 1632-1635.

19. IGA, D. P., SCHMIDT, R. R., IGA, S., HOTOLEANU, C. L., DUICA, F., NICOLESCU, A., GITMAN, S. S. Turk. J. Chem. 2013, 37, 299-307.

20. MATSUNAGA, E., HIGUCHI, Y., MORI, K., YAIRO, N., OKA, T., SHINOZUKA, S., TASHIRO, K., IZUMI, M., KUHARA, S., TAKEGAWA, K. PLOS ONE 2015, 10(9), e0137230.

21. ALCARO, S., ARENA, A., NERI, S., OTTANA, R., ORTUSO, F., PAVONE B., VIGORITA, M. G. Bioorg. Med. Chem. 2004, 12, 1781-1791.

22. NISIC, F. PhD, Milano, 2009-2010.

23. FAIS, M., KARAMANSKA, R., ALLMAN, S., FAIRHURST, S. A., INNOCENTI, P., FAIRBANKS, A. J., DONOHOE, T. J., DAVIS, B. G., RUSSELL, D. A., FIELD, R. A. Chem. Sci., 2011, 2, 1952-1959.

24. DAHLMAN, O., GAREGG, P. J., MAYER, H., SCHRAMEK, S. Acta Chem. Scand. B 1986, 40, 15-20.

25. DENG, S., YU, B., HUI, Y., YU, H., HAN, X. Carbohydr. Res. 1999, 317, 53-62.

26. HIRSCH, J., AND KOÓŠ, M. Chem. Pap. 2005, 59, 21-24.

27. HORI, T., SUGITA, M., ANDO, S., KUWAHARA, M., KUMAUCHI, K., SUGIE, E., ITASA, O., J. Biol. Chem. 1981, 256, 10979-10985.

28. RICCIO, R., MINALE, L., BANO, S., AHMAD, V. U. Tetrahedron Lett., $1987,28,2291-2294$.
29. KICHA, A.A., KALINOVSKII, A. I., STONIK, V. A. Chem. Nat. Compd., 1990, 25, 569-572.

30. WANG, W., LI, F., HONG, J., LEE, C.-O., CHO, H. Y., IM, K. S., JUNG, J. H. Chem. Pharm. Bull. 2003, 51, 435-439.

31. ABE, F., YAMAUCHI, T. Chem. Pharm. Bull. 2000, 48, 1017-1022.

32. METZLER, D. E., METZLER, C. M., 2003, in Biochemistry, The Chemical Reactions of Living Cells, D. E. METZLER (Ed.), Elsevier, Academic Press, New York, p. 719-762.

33. CROWDER, C. M., WESTOVER, E. J., KUMAR, A. S., OSTLUND, R. E., J., and Covey, D. F. (2001) J. Biol. Chem. 276, 44369-44372.

34. IGA, D. P. Chem. Res. J., 2018, 3, 63-79.

35. FISCHER, E., ARMSTRONG, E. F. Ber. Deut. Chem. Ges. 1902, 35, 3144-3153.

36. FISCHER, E., DELBRÜCK, K. Ber. Deut. Chem. Ges. 1909, 42, 27762785.

37. ARMSTRONG, E. F. 1924, The Carbohydrates and The Glucosides, Longmans, London.

38. FISCHER, E. Ber. Deut. Chem. Ges. 1906, 39, 2893-2931.

39. FIESER, L. F., FIESER, M. F. 1959, Steroids. Reinhold Publishing Corporation: New York.

40. BANERJ I, J., CHATTERJEE, A., ITOH, Y., KIKUCHI, T. Indian J. Chem. 1973, 11, 1056-1057.

41. NAKAO, K., IWADOH, A., HIROTA, T., HAYAKUWA, S. J. Chem. Soc., Chem. Commun. 1987, 1508.

42. MARTIN, R. B., YEAGLE, P. L. Lipids 1978, 13, 594-597.

43. HARRIS, J. S., EPPS, D. E., DAVIO, S. R., KEZDY, F. J. Biochemistry 1995, 34, 3851-3857.

44. HUANG, J., FEIGENSON, G. W. Biophys. J. 1999, 76, 2142-2157.

45. YELAMAGGAD, C. V., SHANKER, G., HIREMATH U. S., KRISHNA PRASAD, S. J. Mater. Chem., 2008, 18, 2927-2949.

46. MUKHERJEE, S., CHATTOPADHYAY, A. Biochemistry 1996, 35, 13111322.

47. MUKHERJEE, S., CHATTOPADHYAY, A. Chem. Phys. Lipids 2005, $134,79-84$.

Manuscript received: 4.12 .2018 